\title{
Diatomaceous earth as source of silicon on the growth and yield of rice in contrasted soils of Southern India
}

\author{
Kollalu Sandhya ${ }^{1}$, Nagabovanalli Basavarajappa Prakash ${ }^{1}$, Jean Dominique Meunier ${ }^{2 *}$ \\ ${ }^{1}$ Department of Soil Science and Agricultural Chemistry, University of Agricultural Sciences, GKVK, Ben- \\ galuru, Karnataka - 560065 India. ${ }^{2}$ Aix-Marseille Univ, CNRS, IRD,Coll Francia, CEREGE, 13545 Aix en \\ Provence, Cedex 04, Francia. *Corresponding author: meunier@cerege.fr
}

\begin{abstract}
Application of diatomaceous earth (DE) could improve the quality of soil, but its application in agriculture as a Si fertilizer requires additional research. Pot experiments were conducted with graded levels $(0,150,300$, $600 \mathrm{~kg} \mathrm{ha}^{-1}$ ) of DE with recommended dose of N, P, K, in three types of soil (acidic, neutral and alkaline) from Southern India under two moisture conditions (field capacity and submergence) using rice as a test crop. The chosen DE consisted of biogenic silica, smectite, kaolinite and quartz. The grain yield was lower in plants grown in FC than in SUB moisture conditions regardless of the soil type and the DE added. Higher grain yield was observed with different DE applications under the SUB moisture condition in the three soils. The Si uptake increased for acidic and alkaline soils but not for neutral soil under the SUB moisture condition, whereas under the FC condition, the Si uptake was increased over the control only in alkaline soil. Increased nutrient and $\mathrm{Si}$ uptake was explained by the combination of physical and chemical properties of DE and was not only due to the contribution of amorphous silica. DE might be useful for improving the crop yield, but the soil composition and water regimes play a key role that influences the availability of nutrients in soils.
\end{abstract}

Keywords: Si fertilizer, moisture regimes, acidic, neutral, alkaline, graded level 


\section{Introduction}

The increasing demand for crop production and productivity can only be met with intensive cropping techniques that further aggravate the use of high-yielding soil-exhausting varieties, fertilizers and crop protection chemicals. The predicted result is deterioration of these agro-ecosystems and soil health. Therefore, an urgent need exists to find solutions that can maintain sustainable production and that include better assessment of the soil biogeochemistry and nutrient dynamics in rice ecosystems (Krishna, 2010). Rice is of one of the most important staple foods worldwide. Similar to most of the cultivated cereals, rice is also considered as a silicon accumulator (Guntzer et al., 2012). Although it has not been recognized as an essential element for plant growth, many studies have documented that Si might be helpful in alleviating various biotic and abiotic stresses and increasing yield even in non-stressed conditions (Camargo et al., 2017; Liang et al., 2015). These beneficial effects of silicon could result in increased production and productivity of rice and should be considered in agricultural practices. $\mathrm{Si}$ is the most common element in the surface of the continent, but the fraction that is bioavailable to plants differs greatly according to the parent rock composition and the degree of weathering (Haynes, 2014). It has been shown that in certain cultivated areas, the available $\mathrm{Si}$ was below the optimal limit required to achieve the predicted yield of rice crops (Prakash, 2002), and hence, the need exists for silicon fertilization. Different types of sources for Si fertilizers have been tested, including industrial by-products and materials extracted from mines (Castro et al., 2016; Liang et al., 2015). However, those sources might be unsuitable due to high cost or high heavy metal content, and others such as diatomaceous earth are not sufficiently documented.
Diatomaceous earth (DE) or diatomite refers to sedimentary rocks that consist primarily of opaline frustules of diatoms (Bates and Jackson, 1987). DE occurs in many areas of the world and has unique physical characteristics, such as high permeability (0.1-10 $\mathrm{mD}$ ) and porosity (35-65\%) (Murer et al., 2000), small particle size, low thermal conductivity and density (Hassan et al., 1999), and high surface area (Gao et al., 2005). DE has proven useful for improving the physical properties of soils. Aksakal et al. (2013) showed that DE protected large aggregate formation in clay-textured soils and decreased the maximum dry bulk density (MBD) but increased the optimum moisture content (OMC). Compared with the control, the highest DE application dose $(30 \%)$ decreased the MBD with the rates of $10.4 \%, 14.0 \%$ and $9.0 \%$ in sandy loam, loam and clay textured soils, respectively, but it increased the OMC values with rates of 49.1 $\%, 42.2 \%$ and $38.5 \%$. The "stretchy" structure of DE also increased the water retention capacity. Although $\mathrm{DE}$ application had no effect on the wilting point $(\mathrm{pF}$ $4.18)$, it significantly increased the field capacity $(\mathrm{pF}$ 2.52 ) of soils. DE acts as an effective amendment to improve the water-holding capacity of light-textured soils sandy soils. Among the substrates tested, the highest water-holding capacity was obtained with application of 30\% DE with a size of 2-4 mm (Angin et al., 2011). Applications of DE to soils have also been proven beneficial to plants by improving the physical properties of soils. Addition of DE increased the root number and length and the leaf area in cull strawberries (Ilker et al., 2011).

A few studies have shown that application of DE can be beneficial for plants as a source of Si. Diatomaceous earth is formed by diatom frustules composed of amorphous $\mathrm{Si}(\mathrm{BSi})$ that is easily soluble compared to the other silicates common in soils (Fraysse et al., 
2009). Rizwan et al. (2012) showed that DE application might reduce the toxicity of $\mathrm{Cd}$ in wheat and attributed this effect to $\mathrm{Si}$, which induced a decrease in available $\mathrm{Cd}$ in the soil. At the plant level, a decrease of Cd translocation to shoots was reported. Abdalla (2010) attributed better morphological increments and nutrient uptake in fava beans treated by DE to Si. Pati et al. (2016) showed that application of DE as $\mathrm{Si}$ fertilizer significantly increased the yield of rice crops in India, but Berthelsen et al. (2003) showed that DE generally did not improve the yield of sugarcane in Australia. Such a discrepancy for crops might be due to environmental conditions such as water regime and geochemical conditions that can affect the dissolution of Si from DE. For instance, the solubility of amorphous silica is limited at low pH (Fraysse et al., 2009). Another factor is the presence of major impurities in the DE that might limit the Si delivered to solution. Many raw DE materials are not entirely composed of diatom frustules but also contain significant amounts of clay minerals, quartz or calcium carbonate (Pedersen et al., 2004; Ilia et al., 2009). Accordingly, the need exist for further research toward an improved understanding of the mechanism by which DE is beneficial in Si uptake and yield of Si accumulators. Based on this background, an investigation was undertaken to better assess the effect of graded levels of DE on Si uptake, growth and yield of rice in Southern India.

\section{Material and Methods}

A study (pot experiment) was conducted at the Department of Soil Science and Agricultural Chemistry, UAS, GKVK, Bengaluru to investigate the dissolution and release of silicon from DE and its effect on the growth and yield of rice. The experiments were performed in three types of soils collected from different locations, namely, acidic (Typic Kandiustults), neutral (Typic ustalfs) and alkaline (Typic Haplus- terts) soils of Karnataka, South India. DE from Agripower Pvt. Ltd, Australia was used in the study. The soils were air dried, crushed to pass through a $2 \mathrm{~mm}$ sieve and used in the experiment. The study began by taking $5 \mathrm{~kg}$ of soil from each location and filling plastic pots treated with graded levels of DE maintained under $100 \%$ of field capacity (FC) and submerged (SUB) moisture conditions for 120 days. The soil was thoroughly mixed with the recommended dose of fertilizer ( $\mathrm{RDF}-100: 50: 50 \mathrm{~N}: \mathrm{P}_{2} \mathrm{O}_{5}: \mathrm{K}_{2} \mathrm{O} \mathrm{kg} \mathrm{ha}^{-1}$ ) for rice and different levels of DE at $0,150,300$ and 600 $\mathrm{kg} \mathrm{ha}^{-1}$ of DE (Table 3) equivalent to rates of $0,0.075$, $0.15,0.3 \mathrm{~g} \mathrm{~kg}^{-1}$ of soil. The experiment consisted of 8 treatments, namely, $\mathrm{T}_{1}$ : FC - RDF alone (control), $\mathrm{T}_{2}: \mathrm{FC}-\mathrm{RDF}+\mathrm{DE} @ 150 \mathrm{~kg} \mathrm{ha}^{-1}, \mathrm{~T}_{3}: \mathrm{FC}-\mathrm{RDF}+\mathrm{DE}$ (a) $300 \mathrm{~kg} \mathrm{ha}^{-1}, \mathrm{~T}_{4}: \mathrm{FC}-\mathrm{RDF}+\mathrm{DE} @ 600 \mathrm{~kg} \mathrm{ha}^{-1}$, $\mathrm{T}_{5}$ : SUB - RDF alone (control), $\mathrm{T}_{6}: \mathrm{SUB}-\mathrm{RDF}+\mathrm{DE}$ @ $150 \mathrm{~kg} \mathrm{ha}^{-1}, \mathrm{~T}_{7}$ : SUB - RDF+DE @ $300 \mathrm{~kg} \mathrm{ha}^{-1}$ and $\mathrm{T}_{8}$ : SUB - RDF+DE@600 kg ha-1. Each treatment was performed in triplicate. Rice seedlings (variety: JGL 1798) at the age of 21 days were transplanted into the pots and the moisture content was maintained at field capacity and submerged conditions. The plant samples were collected at harvest and subjected to the analysis described below.

\subsection{Plant sample processing and silicon analysis}

Rice plants were washed with distilled water to remove soil contamination. Plant samples were dried in an oven at $75^{\circ} \mathrm{C}$ until a constant dry weight was obtained. The dry plant samples were weighed, ground to a fine powder and used in further analysis. Panicles were separately collected and grains were separated from the panicles. The grain weight was observed and analyzed for Si content.

The powdered grain and straw samples were dried in an oven at $70{ }^{\circ} \mathrm{C}$ for $2-3 \mathrm{hrs}$ prior to analysis. The sample $(0.1 \mathrm{~g})$ was digested in a mixture of $7 \mathrm{ml}$ of 
$\mathrm{HNO}_{3}\left(70 \%, 2 \mathrm{ml}\right.$ of $\mathrm{H}_{2} \mathrm{O}_{2}(30 \%)$ and $1 \mathrm{ml}$ of $\mathrm{HF}$ (40 $\%)$ using a microwave digestion system (Milestonestart D) with the following steps: 1000 watts for 17 minutes, 1000 watts for 10 minutes and venting for 10 minutes. The digested samples were diluted to $50 \mathrm{ml}$ with 4 percent boric acid (Ma and Takahashi, 2002). The Si concentration in the digested solution was determined as described. An amount of $0.5 \mathrm{ml}$ of the digested aliquot was transferred to a plastic centrifuge tube, to which was added $3.75 \mathrm{ml}$ of $0.2 \mathrm{~N} \mathrm{HCl}$, $0.5 \mathrm{ml}$ of $10 \%$ ammonium molybdate $\left(\left(\mathrm{NH}_{4}\right)_{6} \mathrm{Mo}_{7} \mathrm{O}_{2}\right)$, $0.5 \mathrm{ml}$ of $20 \%$ tartaric acid and $0.5 \mathrm{ml}$ of reducing agent (amino naphtholsulfonic acid-ANSA), and the volume was topped up to $12.5 \mathrm{ml}$ with distilled water. After one hour, the absorbance was measured at 600 $\mathrm{nm}$ with a UV-visible spectrophotometer (Shimadzu) (Ma and Takahashi, 2002). Standards (0, 0.2, 0.4, 0.8 and $\left.1.2 \mathrm{mg} \mathrm{l}^{-1}\right)$ were prepared using Merck Certipur solution $\left(1000 \mathrm{mg} \mathrm{l}^{-1}\right)$.

\subsection{Soil and DE analysis}

The soil and DE were analyzed before the experiment for their physicochemical properties. Soil $\mathrm{pH}$ and EC were measured in a suspension with a 1:2.5 water ratio. The soil textural class was determined by following the International Pipette method (Jackson, 1973). Available N was determined by the alkaline potassium permanganate method (Subbaiah and Asija, 1949). Available $\mathrm{P}_{2} \mathrm{O}_{5}$ was estimated by Bray's method (Bray and Kurtz, 1945) for acidic and neutral soils and by the Olsen method (Olsen, 1954) for alkaline soil. Available $\mathrm{K}$ and exchangeable $\mathrm{Ca}$ and $\mathrm{Mg}$ were extracted using $1 \mathrm{~N}$ ammonium acetate and $\mathrm{K}$ was analyzed using flame photometry (Jackson, 1973). Exchangeable $\mathrm{Ca}$ and $\mathrm{Mg}$ were determined by the complexometric titration method (Baruah and Barthakur, 1997). Soluble silicon concentration available for plant (PAS) was determined by soil extraction using $0.01 \mathrm{M} \mathrm{CaCl}_{2}$, and $\mathrm{Si}$ was measured using UVvisible spectrophotometry (Haysom and Chapman, 1975). The field capacity of soil was determined using a pressure plate apparatus (Baruah and Barthakur, 1997) at laboratory condition.

The mineralogical compositions were determined by $\mathrm{X}$-ray diffraction (XRD) on powdered samples using a Philips MPD 3710 (Co anti-cathode) X-ray diffractometer. The DE composition was also determined using a scanning electron microscope (SEM) (JEOL JSM-6320F) equipped with energy-dispersive X-ray spectroscopy (EDS) with a Si-Li detector (Quantax, Bruker AXS Microanalysis, GmbH Berlin, Germany) at CINaM-CNRS-Aix-Marseille Université. Major elements of DE were determined by inductively coupled plasma optical emission spectrometer (ICP-OES Jobin-Yvon, Ultima-C) at CEREGE after alkaline fusion (Germanique, 1994)

\subsection{Statistical analysis}

Comparisons between treatments were statistically analyzed using one-way ANOVA at a significance level of $\mathrm{P}<0.05$ via the Fisher test using XLSTAT (Addinsoft 2017. XLSTAT 2017: Data Analysis and Statistical Solution for Microsoft Excel. Paris, France, 2017).

\section{Results}

\subsection{Soil and DE composition}

The study soils (Table 1) were characterized using a large range of $\mathrm{pH}$, from 4.48 (acidic) to 8.86 (alkaline). Soil EC was found to be in the normal range $(<$ $\left.0.8 \mathrm{dSm}^{-1}\right)$ in all soils but higher in alkaline soil $(0.74$ $\left.\mathrm{dSm}^{-1}\right)$. The texture was dominated by the sand fraction in the 3 soils with the highest values for neutral soil (conversely with the lowest value for silt), where- 
as the percentage of the clay fraction was roughly the same (23 to $27 \%$ ). Quartz, feldspar, and muscovite were detected in all three soils.
Chlorite was detected in acidic and alkaline soils and amphibolite only in alkaline soils (Figure 1).

Table 1. Physicochemical properties of acidic, neutral and alkaline soil. For duplicate analysis, average values are indicated with \pm SD.

\begin{tabular}{|c|c|c|c|c|}
\hline \multicolumn{2}{|c|}{$\mathrm{pH}(1: 2.5$ water $)$} & $4.48 \pm 0.03$ & $6.51 \pm 0.23$ & $8.86 \pm 0.11$ \\
\hline \multicolumn{2}{|c|}{$\mathrm{EC}\left(\mathrm{dSm}^{-1}\right)(1: 2.5$ water $)$} & $0.34 \pm 0.03$ & $0.20 \pm 0.03$ & $0.74 \pm 0.08$ \\
\hline \multirow{3}{*}{$\begin{array}{l}\text { Particle size } \\
\text { Distribution }\end{array}$} & Sand $(\%)$ & 51 & 71 & 42 \\
\hline & Silt (\%) & 22 & 6 & 29 \\
\hline & Clay $(\%)$ & 27 & 23 & 28 \\
\hline \multicolumn{2}{|c|}{ Textural class } & Sandy clay loam & Sandy clay loam & Clay loam \\
\hline \multicolumn{2}{|c|}{ Field capacity $(\%)$} & 30.5 & 28.30 & 40.39 \\
\hline \multicolumn{2}{|c|}{$0.01 \mathrm{M} \mathrm{CaCl}_{2}-\mathrm{Si}(\mathrm{ppm})$} & $18.01 \pm 0.08$ & $61.22 \pm 2.04$ & $46.18 \pm 1.19$ \\
\hline \multicolumn{2}{|c|}{ Available $\mathrm{N}\left(\mathrm{kg} \mathrm{ha}^{-1}\right)$} & $274 \pm 2.83$ & $324.0 \pm 2.12$ & $269.0 \pm 1.41$ \\
\hline \multicolumn{2}{|c|}{ Available $\mathrm{P}_{2} \mathrm{O}_{5}\left(\mathrm{~kg} \mathrm{ha}^{-1}\right)$} & $36.59 \pm 1.53$ & $95.10 \pm 1.48$ & $21.33 \pm 0.91$ \\
\hline \multicolumn{2}{|c|}{ Available $\mathrm{K}_{2} \mathrm{O}\left(\mathrm{kg} \mathrm{ha}^{-1}\right)$} & $203 \pm 3.54$ & $257 \pm 3.54$ & $197.0 \pm 2.83$ \\
\hline \multicolumn{2}{|c|}{ Exch.Ca $\left(\mathrm{cmol}\left(\mathrm{p}^{+}\right) \mathrm{kg}^{-1}\right)$} & $2.35 \pm 0.23$ & $5.50 \pm 0.37$ & $21.15 \pm 1.15$ \\
\hline \multicolumn{2}{|c|}{ Exch. $\mathrm{Mg}\left(\mathrm{cmol}\left(\mathrm{p}^{+}\right) \mathrm{kg}^{-1}\right)$} & $1.10 \pm 0.09$ & $2.40 \pm 0.06$ & $10.95 \pm 0.49$ \\
\hline
\end{tabular}

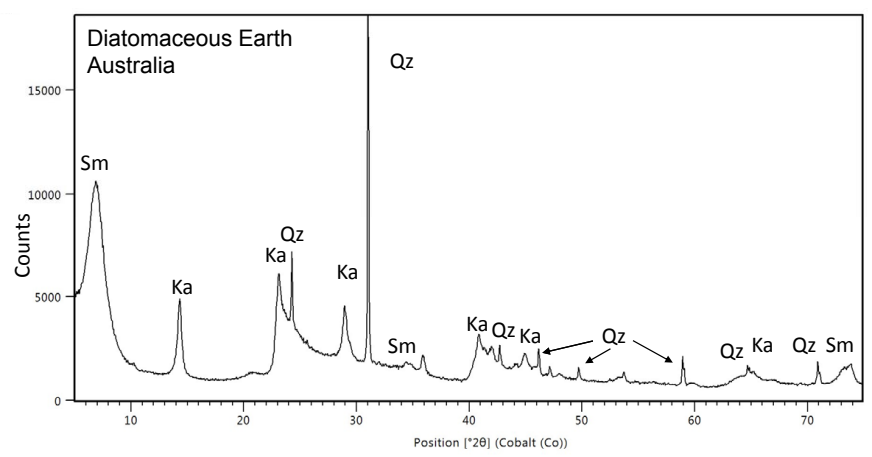

Figure 1. X-ray diffractogram of the diatomaceous earth (DE) used in the experiments (Qz, quartz; Sm, smectite; 
The composition of secondary minerals was found to display significant variation as well. Goethite was detected in neutral soil, gibbsite in acidic soil, kaolinite in acidic and neutral soils and smectite in alkaline soil only. Carbonates (calcite) were detected in alkaline soil. Neutral soil had more all nutrients compared to acidic and alkaline soils (Table 1), whereas $\mathrm{Ca}$ and $\mathrm{Mg}$ were found to be high in alkaline soil. $\mathrm{CaCl}_{2}$-extractable $\mathrm{Si}$ was higher in neutral soil (61.22 ppm) followed by alkaline (46.18 ppm) and acidic (18.01 ppm) soils. DE was characterized by an alkaline $\mathrm{pH}$ (9.21) and an electrical conductivity similar to that of alkaline soil. $\mathrm{CaCl}_{2}$-extractable $\mathrm{Si}$ of DE (473 ppm) was an order of magnitude higher than values found in the soil (Table 2).

Table 2. Composition of diatomaceous earth.

\begin{tabular}{lc}
\hline \multicolumn{1}{c}{ Properties } & Values \\
\hline $\mathrm{pH}(1: 2.5$ water $)$ & 9.21 \\
$\mathrm{EC}\left(\mathrm{dSm}^{-1}\right)(1: 2.5$ water $)$ & 0.72 \\
Particle size $(\mu \mathrm{m})$ & $10-200^{*}$ \\
Cation exchange capacity & 52.00 \\
$\left.\left(\mathrm{cmol}^{+}\right) \mathrm{kg}^{-1}\right)$ & \\
$\mathrm{Al}_{2} \mathrm{O}_{3}(\%)$ & 18.3 \\
$\mathrm{CaO}(\%)$ & 1.6 \\
$\mathrm{Fe}_{2} \mathrm{O}(\%)$ & 4.9 \\
$\mathrm{~K}_{2} \mathrm{O}(\%)$ & 0.4 \\
$\mathrm{MgO}(\%)$ & 3.0 \\
$\mathrm{MnO}(\%)$ & 0.0 \\
$\mathrm{Na}_{2} \mathrm{O}(\%)$ & 1.2 \\
$\mathrm{P}_{2} \mathrm{O}_{5}(\%)$ & 0.1 \\
$\mathrm{SiO}_{2}(\%)$ & 54.8 \\
$\mathrm{TiO}_{2}(\%)$ & 0.5 \\
$\mathrm{LOI}^{(\%)}$ & 12.3 \\
$\mathrm{Total}$ & 97.2 \\
$\mathrm{CaCl}_{2} \mathrm{Si}(\mathrm{ppm})$ & 472.81 \\
\hline
\end{tabular}

*AgriPower Australia, written communication

$\mathrm{DE}$ also contained significant amount of $\mathrm{Al}_{2} \mathrm{O}_{3}$, $\mathrm{Fe}_{2} \mathrm{O}_{3}$ and $\mathrm{MgO}$ and the XRD analysis showed a predominance of quartz, kaolinite and smectite (Figure 1). The existence of amorphous silicon was not clearly identified because no characteristic peak was observed at $26-27^{\circ} 2 \theta$, a characteristic identification technique revealed by Dixon and Weed, (1989). However, the presence of diatom tests was confirmed under SEM together with sponge spicules (Figure 2). 

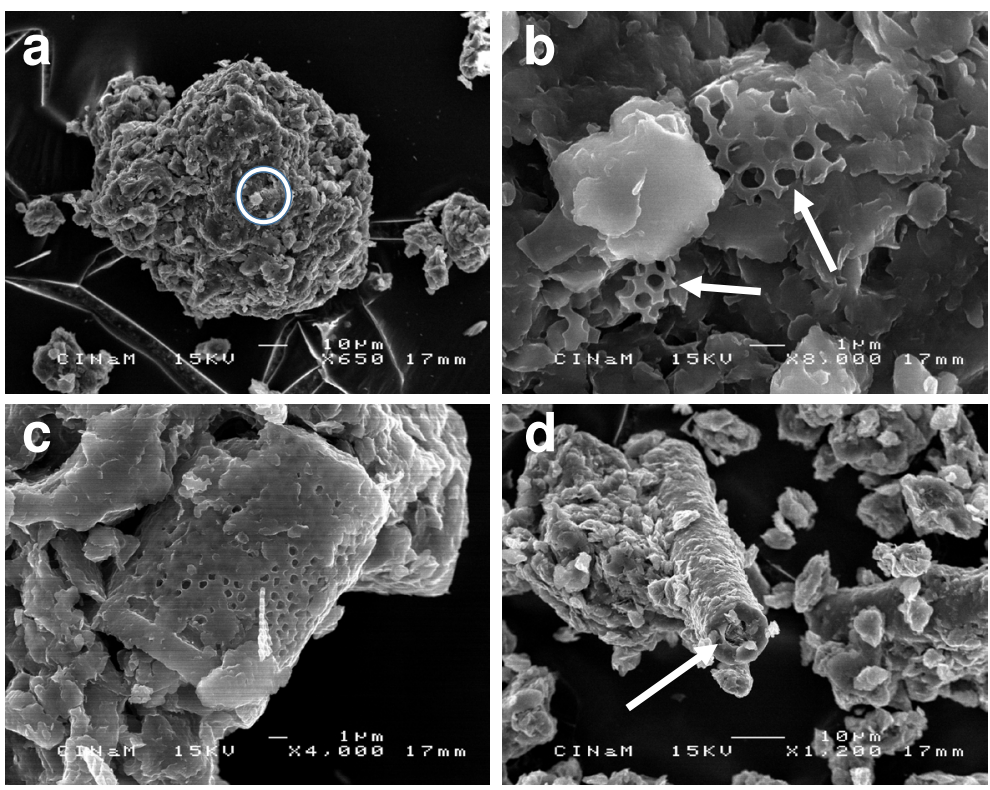

Figure 2. SEM microphotographs of the diatomaceous earth (DE) used in the experiments. a) aggregate showing that the material is not entirely composed of diatom frustules, where the circle shows the location of b); b) close up of the circle in a) showing two fragments of diatom frustules (arrows); c) a well preserved diatom frustule; d) material containing a sponge spicule (arrow).

\subsection{Straw biomass and grain yield}

Lower biomass was recorded in alkaline soil (from 0.5 to $6.8 \mathrm{~g} \mathrm{pot}^{-1}$ ) compared to acidic soil (from 6.2 to $14.6 \mathrm{~g} \mathrm{pot}^{-1}$ ) and neutral soil (from 9.4 to $20.1 \mathrm{~g}$ pot $^{-1}$ ) if all treatments (DE added and moisture condition) are taken as a whole. Straw biomass (g pot $\left.{ }^{-1}\right)$ was higher at the SUB than at the FC moisture condition in all treatments for acidic soil and in all treatments except for the control for alkaline soils (Figure 3). For neutral soil, straw biomass was generally not significantly different of the two moisture conditions. For a given moisture condition, the effect of DE application was contrasted among soils, and no regular increase of straw biomass was recorded with graded levels of added DE. However, compared to the control, application of $600 \mathrm{~kg} \mathrm{DE} \mathrm{ha}^{-1}$ significantly increased the straw biomass grown in acidic and neutral soils under the SUB condition and in alkaline soil under both the SUB and FC moisture conditions. Under the FC moisture condition, DE application did not increase the straw biomass for acidic and neutral soils.

The grain yield was lower in plants grown on FC than on SUB moisture conditions regardless of the soil type and the levels of DE application (Figure 3). Higher grain yield was observed with the highest rate of DE application (600 kg DE ha-1) under the SUB moisture condition in all three soils. Under the SUB moisture condition, the increase in yield, calculated as $=100 \mathrm{x}$ ((yield at $600 \mathrm{~kg} \mathrm{DE} \mathrm{ha-1}$-yield without DE)/ (yield without DE)), was recorded as $+29 \pm 8 \%$ for acidic soil, $+19 \pm 11 \%$ for neutral soil and $+455 \pm 106$ $\%$ for alkaline soil. Under the FC moisture condition, grain yield increase was observed in acidic soil at 150 
and $600 \mathrm{~kg} \mathrm{DE} \mathrm{ha}^{-1}$ and in neutral soil at $150 \mathrm{~kg} \mathrm{DE}$ $\mathrm{ha}^{-1}$. For straw biomass, the grain yield presented a roughly lower range of values for alka line soil (from 0.7 to $5.2 \mathrm{~g} \mathrm{pot}^{-1}$ ) than for acidic soil (from 2.7 to $9 \mathrm{~g}$ pot $^{-1}$ ) and neutral soil (from 4.1 to $12.6 \mathrm{~g} \mathrm{pot}^{-1}$ ).
For intermediate DE treatments under the SUB condition, the results were contrasted. The maximum grain yield was achieved at only $300 \mathrm{~kg} \mathrm{DE} \mathrm{ha}^{-1}$ for acidic soils and was even lower for alkaline soil at $150 \mathrm{~kg} \mathrm{DE} \mathrm{ha-1}$.

Acidic soil
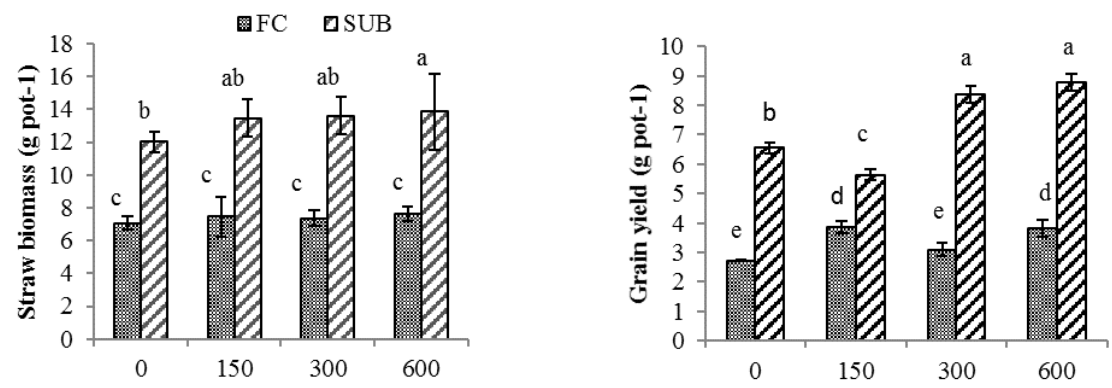

Neutral soil
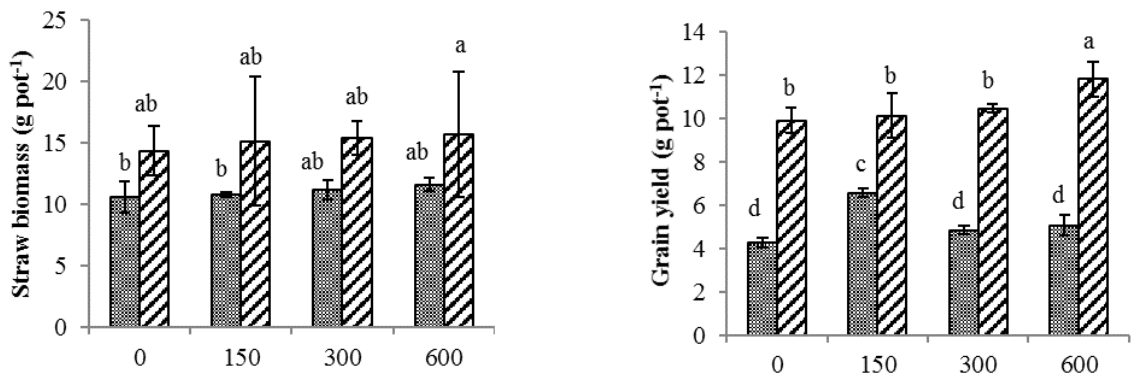

Alkaline soil
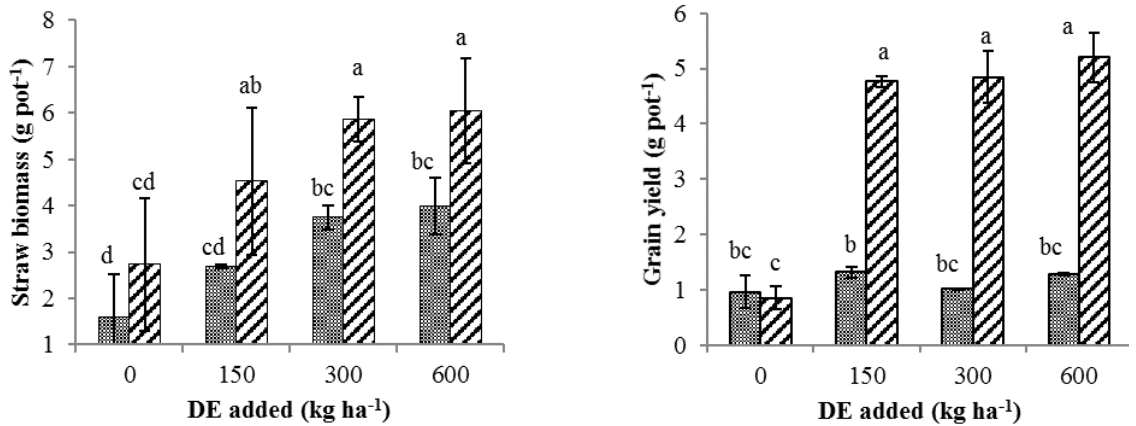

Figure 3. Effect of graded levels of diatomaceous earth on straw and grain yield $\left(\mathrm{g} \mathrm{pot}^{-1}\right)$ under field capacity and submergence moisture conditions in acidic, neutral and alkaline soils. Each value represents the mean value of 3 replications; values having same letters do not differ significantly at $\mathrm{P} \leq 0.05$. 


\subsection{Straw and grain $\mathrm{Si}$}

Higher straw Si content was observed in neutral soil (range $=6.3-8.3 \% \mathrm{Si})$ than in alkaline soil (range $=$ $5-6.6 \% \mathrm{Si}$ ) and acidic soil (range $=4-5.3 \% \mathrm{Si}$ ) (Figure 4), whereas grain $\mathrm{Si}$ content roughly decreased in the same range in all three types of soils $(0.4-1.2 \% \mathrm{Si})$ (Figure 4). Plants treated with the highest level of DE recorded higher straw Si content than the control for neutral and alkaline soils under the SUB condition and for acidic and alkaline soils at the FC conditions, but no clear trend was observed among the intermediate treatments. Generally, we did not observe a significant difference in straw Si content between moisture regimes for a given treatment. An increase in grain Si content between the control and the highest level of DE was observed under the SUB condition in alkaline soil only. Under the FC condition, treatments of different levels of DE did not significantly affect the grain Si content for each soil.

Acidic soil
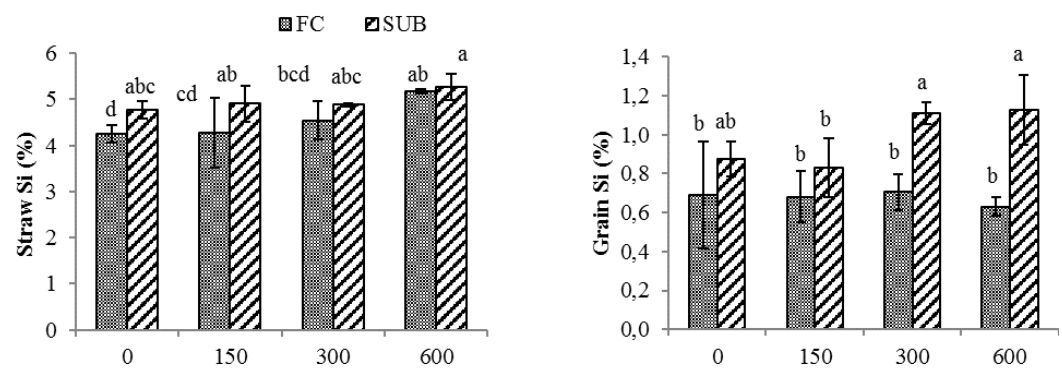

Neutral soil
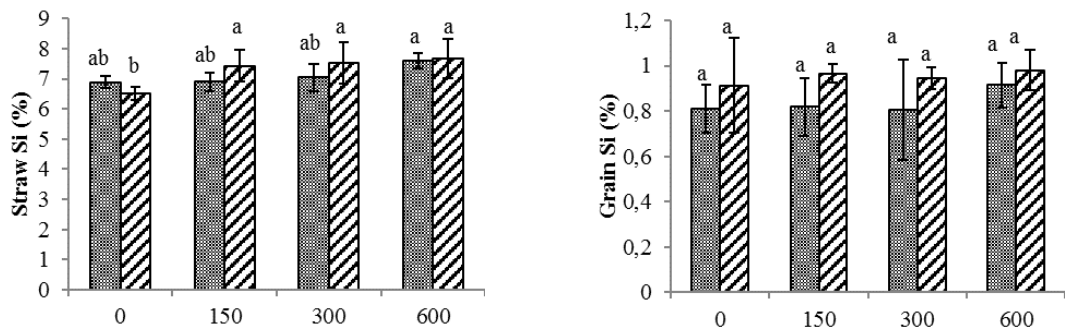

Alkaline soil
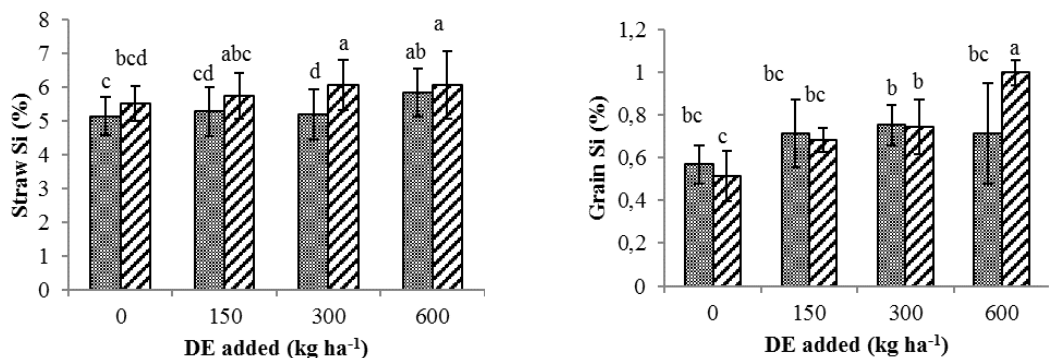

Figure 4. Effect of graded levels of diatomaceous earth on straw and grain $\mathrm{Si} \mathrm{( \% )} \mathrm{under} \mathrm{field} \mathrm{capacity} \mathrm{and} \mathrm{submergence}$ moisture conditions in acidic, neutral and alkaline soils. Each value represents the mean value of 3 replications; values having same letters do not differ significantly at $\mathrm{P} \leq 0.05$. 


\subsection{Total Si (straw + grain) uptake}

Total Si uptake was calculated by summation (biomass straw x Si straw) +(biomass grain x Si grain). As expected, the Si uptake under the SUB conditions was generally higher than under the FC condition. The highest values were obtained for neutral soil (both moisture
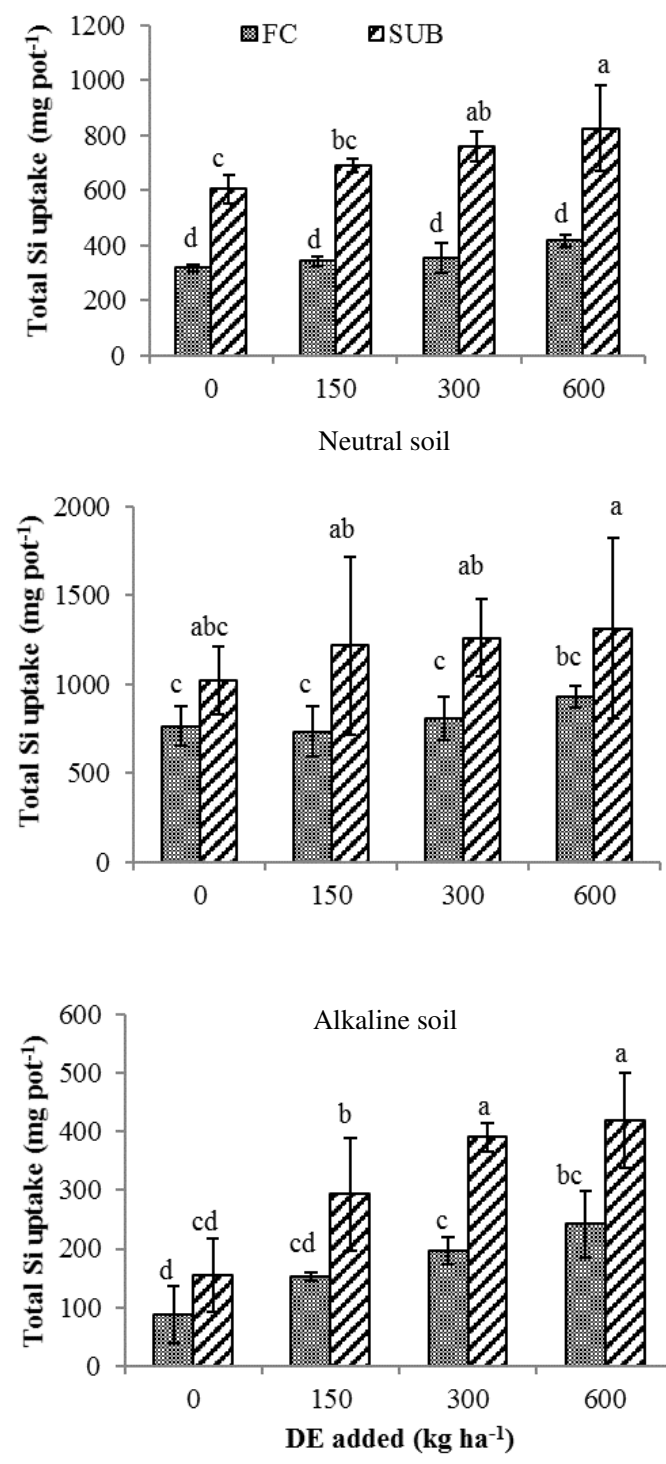

conditions) followed by acidic soils and alkaline soils (Figure 5). With increasing DE application, $\mathrm{Si}$ uptake increased linearly for acidic and alkaline soil but not in neutral soil under the SUB moisture condition, whereas under the FC condition, Si uptake was increased over the control only in the alkaline soil.

Figure 5. Effect of graded levels of diatomaceous earth on total Si uptake $\left(\mathrm{mg} \mathrm{pot}^{-1}\right)$ under field capacity and submergence moisture conditions in acidic, neutral and alkaline soils. Each value represents the mean value of 3 replications; values having same letters do not differ significantly at $\mathrm{P} \leq 0.05$.

\section{Discussion}

\subsection{Control of Si uptake by rice without DE appli- cation}

The uptake of Si by plants depends on the concentration of dissolved Si (DSi) (Ma and Takahashi, 2002), which is ultimately a function of the solubility of the soil-forming silicate minerals and water availability (Cornelis and Delvaux, 2016). Therefore, the uptake of Si can be expected to vary between a lower bound represented by highly weathered soils in a dry condition and a higher bound represented by poorly weathered soil in a humid condition. Comparing the Si uptake for the treatments without DE, our data showed the importance of soil type and water availability in explaining the different results in Figure 4 and 5. The higher Si uptake observed for SUB compared to FC in acidic soil (Figure 5) demonstrated the importance of water for Si uptake, as previously documented in South Australia soils for wheat (Schultz and French, 1978). Such a result showed that the limiting factor 
for accumulation of $\mathrm{Si}$ in rice was water and not the pool of PAS in acidic soil. In this work, the acidic soil showed evidence of a higher degree of weathering compared to the other soils with the presence of gibbsite and the lowest value of $\mathrm{Si}$ extracted by $\mathrm{CaCl}_{2}$ (Table 1) but still contained a significant amount of primary and secondary silicates. Acidic soil was also less fertile than neutral soil with respect to the lower number of available nutrients (Table 1). In acidic soil, we suggest that an increase in the amount of water added to the soils results in more favorable interactions with the mineral surface, which enhances the dissolution of silicates (Haynes, 2014). A slightly different situation might occur in neutral and alkaline soils because the difference in Si uptake between FC and SUB is not significantly different. Water in these soil types might not be a limiting factor for Si uptake because of the more significant pool of PAS. To explain the higher Si uptake in neutral soil compared to alkaline soils, two factors can be mentioned, namely, the stress conditions induced by higher salt content, as indicated by the higher electrical conductivity of the alkaline soil (Table 1), and the texture of the alkaline soil, which was less sandy than the neutral soil and might have affected the crop growth because of less favorable access to water for the roots. Phytoliths have not been investigated in this work although their presence was attested in a majority of soils and might constitute a preferential source of $\mathrm{Si}$ for plants because they dissolve faster than most of the other soil silicates, especially at alkaline $\mathrm{pH}$ (Fraysse et al., 2009). A few studies indicated that the phytolith pool is depleted in cultivated land (Clymans et al., 2011) because of straw exportation from the field. In the cases studied in this work, a fraction of straw was reincorporated into the field according to the farmers, and thus it can be assumed that the phytolith contents of the soils were not completely depleted and could constitute a source for $\mathrm{Si}$. Therefore, we speculate that the phytolith pool might be more heavily depleted in alkaline soil and still more significant in neutral and acidic soils. Quartz was common in the 3 soils and was generally considered to be inert as a source of Si for plants. However, the solubility and dissolution rates of quartz are higher in alkaline solution and in the presence of electrolytes (Dove and Elston, 1992). The $\mathrm{pH}$ values of 9 and the presence of salts, as shown by the higher EC values (Table 1), indicated that quartz dissolution cannot be ruled out for alkaline soil (Knauss and Wolery, 1988)

\subsection{Origin of Si uptake from DE application}

Our findings offered evidence from ICP-AES, XRD and SEM analyses that the DE used in the study was not composed entirely of diatom frustules (amorphous silica) but also consisted of silicates (contributed from different type of clays) and other categories of biogenic silica (BSi) particles such as sponge spicules (Figure 1 and 2). The BSi particles detected in SEM were probably composed of amorphous silica because opal-C or cristobalite, although common in other DE (Eichhubl and Behl, 1998), were not detected by XRD. An estimate of the contribution of Si from DE added into the pots (as calculated from the chemical composition given in Table 2) was calculated from the difference between $\mathrm{Si}$ uptake by rice for a given level of DE minus the uptake by the control (Table 3). The Si uptake by the roots was not measured, but it can be estimated as only $10 \%$ of the uptake by shoots (Jeon, 2006). The calculated percentage of shoot uptake from DE ranged from $57-79 \%$ in acidic soils to $40-57 \%$ in neutral soils and $59-152 \%$ in alkaline soils. These estimates were not in good agreement with our XRD data, which should have shown a peak at 26$27^{\circ} 2 \Theta$ if the DE contains $40 \%$ of amorphous silica. Therefore, we suggested that other sources of Si from $\mathrm{DE}$, such as quartz and clay minerals, might have 
contributed to the Si uptake by rice. This reasoning can also serve as a possible mechanism/evidence for the significant response of rice to applied DE, as noted by Pati et al. (2016). As observed in the present investigation, the theoretical percentage of shoot uptake from DE was $>100$ in alkaline soil (Table 3). The dissolution of Si from DE alone cannot be the only contributor to such a high value in alkaline soil and suggests enhanced dissolution of silica sources from the soil. Such a hypothesis is in good agreement with the previous findings that addition of DE might improve water retention (Sahin et al., 1997), and as a consequence, might drive better adsorption of the nutrients and Si.

Table 3. Estimation of the uptake of Si by DE added in the soils.

\begin{tabular}{|c|c|c|c|c|c|c|c|}
\hline \multirow{3}{*}{ Treatments } & \multicolumn{2}{|c|}{ Acidic (SUB) } & \multicolumn{2}{|c|}{ Alkaline (FC) } & \multicolumn{3}{|c|}{ Alkaline(SUB) } \\
\hline & 300 & 600 & 300 & 600 & 150 & 300 & 600 \\
\hline & \multicolumn{7}{|c|}{$\mathrm{kg} \mathrm{ha}^{-1}$} \\
\hline $\mathrm{Si}$ added per pot as DE $\left(\mathrm{mg} \mathrm{pot}^{-1}\right)$ & 192 & 384 & 192 & 384 & 91 & 192 & 384 \\
\hline $\begin{array}{l}\text { Uptake of Si by shoot and grain } \\
\text { over control }\left(\mathrm{mg} \mathrm{pot}^{-1}\right)\end{array}$ & 152 & 220 & 109 & 154 & 138 & 235 & 265 \\
\hline $\begin{array}{l}\text { Theoretical \% age shoot Si uptake } \\
\text { from DE }\end{array}$ & 79 & 57 & 57 & 40 & 152 & 107 & 59 \\
\hline
\end{tabular}

\subsection{Contrasted effect of $D E$ on yield}

Comparisons between two moisture regimes show significantly higher yield values for SUB than FC for acidic and neutral soils but not for alkaline soil without $\mathrm{DE}$ addition. As discussed previously for Si uptake, the availability of nutrients depends on the water availability in acidic and neutral soils, but in alkaline soil, higher clay content combined with salinity prevents the growth of rice. The correlation between the Si concentration in the shoots and the yield can be used as a demonstration of the benefits of Si to crops (Ma and Takahashi, 2002). In this work, such a plot for the data as whole showed a significant correlation (Figure 6a). However, a closer look (Figure 6b) indicated that for a given soil and moisture condition (corresponding to 12 data), the correlation was only slightly significant for alkaline soils in the SUB conditions. Both param eters (yield and straw Si content) tended to increase from the FC to the SUB condition for neutral and acidic soils. Therefore, our data showed that the Si content of straw was generally not a good representation of the effect of DE addition for explanation of the increase in the yield. The increase in yield due to Si application is not new and has been documented previously using DE (Pati et al., 2016) and many other sources (Liang et al., 2015). We confirmed the dissolution and release of silicon in our previous incubation experiment (Prakash et al., 2016) over different intervals of up to 120 days in acidic and alkaline soil and noted higher PAS with the application of DE compared to the control in both types of soil. However, DE was able to affect the PAS of the soil and also plant growth due to it content of various nutrients (Table 1). Although we did not measure the available $\mathrm{N}, \mathrm{P}$ and $\mathrm{K}$ for $\mathrm{DE}$, according to the total content of $\mathrm{P}_{2} \mathrm{O}_{5}$ and $\mathrm{K}_{2} \mathrm{O}(0.1$ and $0.4 \mathrm{wt} \%$, respectively, Table 1), application of $600 \mathrm{~kg}$ ha $^{-1}$ of DE can supply $0.39 \mathrm{~kg} \mathrm{ha}^{-1}$ of $\mathrm{P}_{2} \mathrm{O}_{5}$ and 2.22 
of $\mathrm{K}_{2} \mathrm{O} \mathrm{kg} \mathrm{ha}{ }^{-1}$. These values were quite small compared to the nutrient content of the soils and of the RDF applied. Accordingly, the nutrient added to the soils by DE application cannot explain the increase in the yield. In this work, the slightly better response for acidic soil than for neutral soil at SUB - RDF+DE@600 kg ha ${ }^{-1}$ ( + $29 \pm 8 \%$ and $19 \pm 11 \%$, respectively ) was in good agreement with the study by Tavakkoli et al. (2011) for Si and biomass production (grain yield not shown), offering evidence that acidic weathered soils were more depleted in PAS and were more reactive to Si fertilization.
The increase in nutrient availability following Si application is well documented but the mechanisms remain unclear (Liang et al., 2015). The increase of DSi might have desorbed $\mathrm{P}$ from the mineral surfaces and allowed it to become more bioavailable. However, such a mechanism depends on $\mathrm{pH}$ because the adsorption of $\mathrm{Si}$ increases with increasing $\mathrm{pH}$ and achieves a peak at pH 9 (Parfitt, 1978; Beckwith and Reeve, 1963), whereas the opposite occurs for $\mathrm{P}$ (Obihara and Russel, 1972).A more positive response for alkaline soil $(+455 \pm 106 \%)$ would be in a good agreement with the mechanism of $\mathrm{Si} / \mathrm{P}$ displacement.
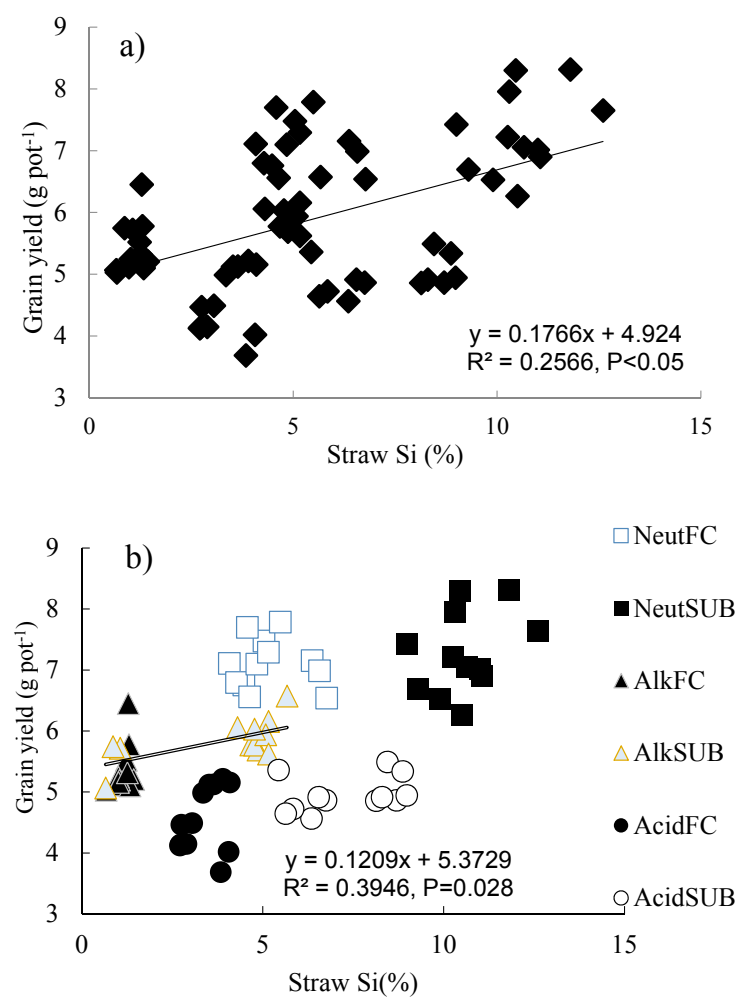

Figure 6. Plot of straw Si concentration (in dry weight \%) vs. grain yield for the data as a whole (a) and b) for the 6 soil/moisture conditions in the studied cases; only significant linear regression equations are given. 
Additionally, DE might have adsorbed more soluble salts, including sodium, which mainly inhibited root development and establishment of the crop and thereby improved yield under alkaline soils. In addition, in acidic conditions, supplemental input of DSi might have reduced the toxicity of metals such as $\mathrm{Al}$ and indirectly influenced the better plant growth (Wallace, 1993). Alkaline soils, which are also affected by salinity, gave the best response to DE for yield with values up to $455 \%$, which is probably the highest reported value. Under the alkaline soil condition, the roots of the plant are highly affected in the early stage of their establishment. Especially under the high salt content of the soils, root establishment is restricted to a greater extent. In the current study, growth and establishment of the transplanted rice under SUB in alkaline soil experienced similar stress, and the straw and yield levels were quite low. The addition of DE greatly improved the yield, but the values remained low compared to the other soils. The dramatic increase of the yield in such a stressed soil demonstrates the capacity of DE to improve the rice growth. Such an improvement was probably the result of a combination of $\mathrm{Si}$ and the physical property of the DE material. In addition, applied Si as a DE source must have stimulated the plants to absorb higher $\mathrm{K}^{+}$(data not reported) under salt stress, as noted by Liang (1999). Potassium plays an important role in contributing to the survival of crop plants under salt stress (Cakmak, 2005, Mahdieh et al, 2015).

\section{Conclusions}

Without DE application, we showed that the water regime is not a limiting factor for $\mathrm{Si}$ and nutrient uptake in alkaline soil. Application of DE on soils fertilized by RDF significantly increased the grain yield from $150 \mathrm{~kg} \mathrm{ha}^{-1}$ for alkaline soil, $300 \mathrm{~kg} \mathrm{ha}^{-1}$ for acidic soil and $600 \mathrm{~kg} \mathrm{ha}^{-1}$ for neutral soil at the SUB conditions, whereas at field capacity, the increase in yield was not significant. The total Si uptake was significant only for acidic soil at the SUB conditions at $600 \mathrm{~kg} \mathrm{ha}^{-1}$ of DE and for alkaline soil for the SUB and FC conditions. The mineralogical study of the DE used in this study shows that it was not entirely composed of amorphous silica. To explain the excess of Si uptake following DE application, our data suggest that the dissolution of clay minerals and quartz from DE also might have been involved.DE application not only contributed additional $\mathrm{Si}$ for improved plant growth but its specific texture also likely aided in improving the water retention locally and consequently improving the solubilization of $\mathrm{Si}$ and the nutrients. Addition of DE for improved crop yield offers an interesting application in good agreement with previous work. However, the chemistry and mineralogy of the soils and the DE used should be characterized in detail to document the mechanisms of Si and nutrient uptake.

\section{Acknowledgements}

The authors acknowledge Agripower Pvt Ltd, Australia for supply of diatomite. This study was partially supported by the CEFIPRA/IFCPAR project No. 5109-1 titled "Survey of soil-Si pools and contribution of Si fertilization in sustainable rice cultivation in south India". The authors also thank Olivier Grauby and Daniel Borschneck for scientific collaboration.

\section{References}

Abdalla, M.M. 2010. Sustainable effects of diatomite on the growth criteria and phytochemical contents of vicia faba plants. Agric. Biol. J. N. Am. 1, 1076-1089.

Aksakal, E.L., Angin, I., Oztas, T. 2013. Effects of diatomite on soil consistency limits and soil compactibility. Catena. 101, 157-163. 
Angin, I., Kose, M., Aslantas, R. 2011. Diatomite on growth of strawberry. Pak. J. Bot. 43, 573-577.

Baruah, T.C., Barthakur, H.P. 1997. A Textbook of Soil Analysis. Vikas Publishing House Pvt. Ltd.: New Delhi. 334 pp.

Bates, R.L., Jackson, J.A. 1987. Glossary of geology (third edition). Elsevier Science.

Berthelsen, S., Noble, A.D., Kingston, G., Hurney, A., Rudd, A., Garside, A. 2003. Improving yield and ccs in sugarcane through the application of silicon based amendments. Final Report SRDC Project CLW009. CSIRO Land and Water. 138 pp.

Beckwith, R.S., Reeve, R. 1963. Studies on soluble silica in soils. I. The sorption of silicic acid by soil and minerals. Aust. J. Soil Res. 1, 157-168.

Bray, R.H., Kurtz, L.T. 1945. Determination of total organic and available forms of phosphorus in soils. Soil Sci. 59, 39-45.

Cakmak, I. 2005. The role of potassium in alleviating detrimental effects of abiotic stresses in plants. J. Plant Nutr. Soil Sci. 168, 521-530.

Camargo, M.S. de, Bezerra, B.K.L., Vitti, A.C., Silva, M.A., Oliveira, A.L. 2017. Silicon fertilization reduces the deleterious effects of water deficit in sugarcane. J. Soil Sci. Plant Nutr. 17, 99-111.

Castro, G.S.A., Crusciol, C.A.C., da Costa, C.H.M., Ferrari Neto, J., Mancuso, M.A.C. 2016. Surface application of limestone and calcium-magnesiom silicate in a tropical no-tillage system. J. Soil Sci. Plant Nutr. 16, 362-379.

Cornelis, J.T., Delvaux, B. 2016. Soil processes drive the biological silicon feedback loop. Functional Ecology 30, 1298-1310.

Clymans, W., Struyf, E., Govers, G., Vandevenne, F., Conley, D.J. 2011. Anthropogenic impact on biogenic Si pools in temperate soils. Biogeosciences. 8, 2281-2293.
Dixon, J.B. and Weed, S.B. 1989. Minerals in Soil Environments. 2nd Edition, Soil Science Society of America, Madison, 706 pp.

Dove, P.M., Elston, S. 1992. Dissolution kinetics of quartz in sodium chloride solutions: analysis of existing data and a rate model for $25{ }^{\circ} \mathrm{C}$. Geochim. Cosmochim. Acta. 56, 4147-4156.

Fraysse, F., Pokrovsky, O.S., Schott, J., Meunier, J.D. 2009. Surface chemistry and reactivity of plant phytoliths in aqueous solutions. Chem. Geol. 258, 197-206.

Eichhubl, P., Behl, R.J. 1998. Diagenesis, deformation, and fluid flow in the Miocene Monterey Formation of coastal California, in Eichhubl. P., ed., Diagenesis, deformation, and fluid flow in the Miocene Monterey Formation of coastal California: SEPM Pacific Section Special Publication. 83, 5-13.

Gao, B.P., Jiang, F., Zhao, S., Ge, Z. 2005. Studies on the surface modification of diatomite with polyethyleneimine and trapping effect of the modified diatomite for injection project in heavy-oil diatomite. SPE Res. Eval. Eng. 3, 2-12.

Germanique, J.C. 1994. Major, trace and rare-earth elements in fourteen GSL reference Samples. Determination by $\mathrm{x}$-ray fluorescence spectrometry and inductively coupled Plasma optical emission spectrometry. Geostand. Newslett. 18, 91-100.

Guntzer, F., Keller, C., Meunier, J.D. 2012. Benefits of plant silicon for crops: a review. Agron. Sustain. Dev. 32, 201-213.

Hassan, M.S., Ibrahim, I.A., Ismael, I.S. 1999. Diatomaceous deposits of Fayium, Egypt: characterization and evaluation for industrial application. Chinese J. Geochem. 18, 233-24.

Haynes, R.J. 2014. A contemporary overview of silicon availability in agricultural soils. J. Plant Nutr. Soil Sci. 177, 831-844. 
Haysom, M.B.C., Chapman, L. E. M. 1975. Some aspects of the calcium silicate trials at Mackay. Proc. Qld Soc. Sugarcane Technol. 42, 117-122.

Ilker, A., Murat, K., Rafet, A. 2011. Diatomite on growth of strawberry. Pak J. Bot. 43, 573-577.

Ilia, I.K., Stamatakis, M.G., Perraki, T.S. 2009. Mineralogy and technical properties of clayey diatomites from north and central Greece. Cent. Eur. J. Geoscience. 1, 393-403.

Jackson, M.L. 1973. Soil chemical analysis. Prentice hall of india pvt. Ltd. New delhi. 521 pp.

Jeon, W.T. 2006. Rice root distribution and rice-based cropping systems for sustainable soil-rhizosphere management. International Workshop on Sustained Management of the Soil-Rhizosphere System for Efficient Crop Production and Fertilizer Use 16-20 October 2006. Land Development Department, Bangkok 10900 Thailand, 115 pp.

Knauss, K.G., Wolery, T.J. 1988. The dissolution kinetics of quartz as a function of $\mathrm{pH}$ and time at 70 ${ }^{\circ} \mathrm{C}$. Geochim. Cosmochim. Acta. 52, 43-53.

Krishna, K.R. 2010. Agroecosystems of South India: Nutrient dynamics, Ecology and productivity. BrownWalker Press. Boca Raton, Florida USA. 539 pp.

Liang, Y., Nikolic, M., Bélanger, R., Gong, H., Song, A. 2015. Silicon in agriculture. From theory to practice. Springer. $235 \mathrm{pp}$.

Liang, Y.C. 1999. Effects of silicon on enzyme activity, and sodium, potassium and calcium concentration in barley under salt stress. Plant Soil. 209, 217-224.

Ma, J.F., Takahashi, E. 2002. Soil, fertilizer, and plant silicon research in Japan. Elsevier, Amsterdam. $281 \mathrm{pp}$.

Mahdieh, M., Habibollahi, N., Amirjani, M.R., Abnosi, M.H., Ghorbanpour, M. 2015. Exogenous silicon nutrition ameliorates salt-induced stress by improving growth and efficiency of PSII in Oryza sativa L. cultivars. J. Soil Sci. Plant Nutr. 15, 1050-1060.

Murer, A.S., Mobil, E., Mc-Clennen, K.L., Ellison, T.K. 2000. Steam injection project in heavy-oil diatomite. SPE Res. Eval. Eng. 3, 2-12.

Obihara, C.H., Russell, E.W. 1972. Specific adsorption of silicate and phosphate by soils. J. Soil Sci. 23, 105-117.

Olsen, S.R. 1954. Determination of total organic and available forms of phosphorus in soils. Soil Sci. $59,39-45$.

Parfitt, R.L. 1978. Anion adsorption by soils and soil materials. Advances Agronomy 30, 1-50.

Pati, S., Pal, B., Badole, S., Hazra, G.C., Mandal, B. 2016. Effect of Silicon Fertilization on Growth, Yield, and Nutrient Uptake of Rice. Comm. Soil Sci. Plant Anal. 47,284-290.

Pedersen, G.K., Pedersen, S.A.S., Steffensen, J., Pedersen, C.S. 2004. Clay content of a clayey diatomite, the Early Eocene Fur Formation, Denmark. Bull. Geol. Soc. 51, 159-177.

Prakash, N.B. 2002. Status and utilization of silicon in indian rice farming. In Proceedings of the second silicon in agriculture conference, Tsuruoka, Yamagata, Japan. Japanese Soc. Soils Plant Nutr. 1, 266-273.

Prakash, N.B., Anitha, M.S., Sandhya, K. 2016. Behaviour of different levels and grades of diatomite as silicon source in acidic and alkaline soils. Silicon. doi:10.1007/s12633-015-9373-9

Rizwan, M., Meunier, J.D., Miche, H., Keller, C. 2012. Effect of silicon on reducing cadmium toxicity in durum wheat grown in a soil with aged contamination. J. Hazard Mat. 209-210, 326-334.

Sahin, U., Hanay, A., Anapali, O. 1997. Seralarda topraksiz kulturde pomzanin kullanilabilirligi uzeri- 
ne bir arastirma. I. Isparta Pomza Sempozyumu Bildirileri, 26-28 June 1997, Isparta, pp. 133-139.

Schultz, J.E., French, R.J. 1976. Silicon uptake by wheat and its relation to grain yield and water use. Aust. J. Exp. Agri. Anim. Husb. 16, 123-128.

Subbaiah, A.Y., Asija, G.K. 1949. Available nitrogen: alkaline permanganate method. Curr. Sci. 25, 254- 260.
Tavakkoli, E., Lyons, G., English, P., Guppy, C. N. 2011. Silicon nutrition of rice is affected by soil $\mathrm{pH}$, weathering and silicon fertilisation. J. Plant Nutr. Soil Sci. 174, 437-445.

Wallace, A. 1993. Participation of silicon in cationanion balance as a possible mechanism for aluminum and iron tolerance in some graminae. J. Plant Nutr. 16, 547-553. 